\title{
Introducing Concurrent Functional Programming in the Telecommunications Industry
}

\author{
Bjarne Däcker \\ Computer Science Laboratory, Ericsson Utvecklings AB, Box 1505, 12525 Älvsjö, Sweden
}

Key words: Functional programming, Concurrent programming, Technology dissemination

\begin{abstract}
This paper gives an overview of the concurrent functional programming language and its development, dissemination, and use.

Erlang was developed at Ericsson and is used for several large and important telecom systems. It is also available externally, both supported and through open source.

Erlang provides a highly relevant case-study of technology diffusion since its development touches upon many relevant topics such as applied research in the industrial environment and spread of technology through open source.
\end{abstract}

\section{INTRODUCTION}

Telecommunications systems place very difficult demands on the underlying programming and computer technology, such as large number of concurrent activities, systems distributed over several computers, large and complex software systems, software maintenance (reconfiguration, etc.) while the system is in operation, fault tolerance to hardware failures and software errors, etc.

The concurrent functional programming language Erlang [3, 5] was developed as a software technology to meet these requirements and to facilitate the design of telecommunications systems. Section 2 gives a short 
overview over Erlang and the subsequent sections describe how Erlang was developed and experiences from its spread both inside and outside Ericsson.

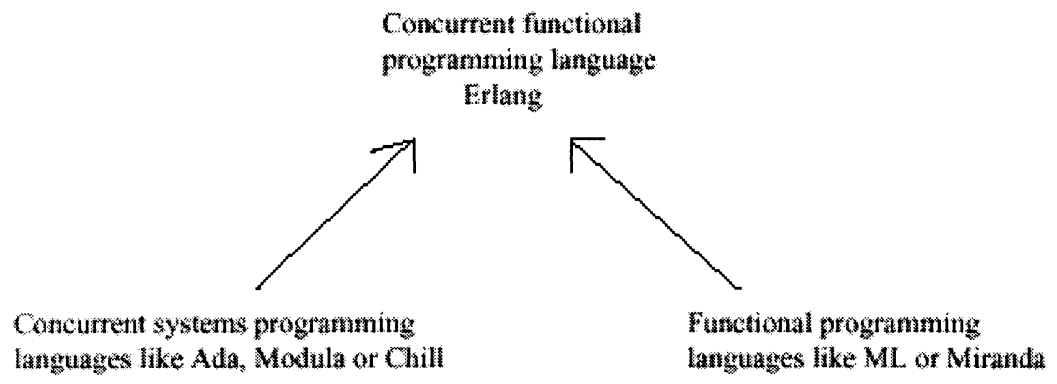

Figure 1. The ancestry of Erlang.

\section{ERLANG}

Erlang is a single assignment, functional programming language language with dynamic typing not unlike Scheme. Its syntax, however, is more like ML or Prolog. Erlang has data types like atoms, numbers, lists, and tuples and uses pattern matching to select between alternatives.

An Erlang program is built up of modules which are separately compiled and loaded. Only explicitly exported functions can be called from another module.

A function can be spawned to create a concurrent process (or "thread of control"). Concurrency is supported by the Erlang implementation without help from the operating system. Processes have no shared memory and communicate by sending and receiving messages asynchronously.

Erlang processes are extremely lightweight and their memory requirements can vary dynamically. Erlang implementations support applications with very large numbers of concurrent processes (typically in the region of 20,000-30,000).

Erlang supports programming "soft" real time systems, which require response times in the order of milliseconds. Long garbage collection delays in such systems are unacceptable, so Erlang is able to reclaim memory in small parts of the system every time the garbage collector is invoked.

Erlang permits transparent distribution. An Erlang program running on a computer is termed an Erlang node. A distributed Erlang system consists of several Erlang nodes spread over many computers (perhaps running different operating systems) connected over a network. Erlang processes in different 
nodes communicate through message passing in the same way as processes within one node.

One Erlang process can crash (because of type error, division by zero etc.) but this will only bring down that process, not the entire node. Erlang processes, however, can monitor each other so that an error can be received as an error message. This enables the design of robust systems where supervisor processes can take action, reclaim resources, log errors, restart a transaction etc.

Erlang allows program code to be changed in a running system (hot code loading). When a new version of a module is loaded, newly spawned processes will run the new version while on-going processes continue and finish undisturbed. It is thus possible to install bug fixes and upgrades in a running system without disturbing its (currently running) operation.

Erlang processes communicate with other programs or the operating system using the same message passing mechanism as is used between Erlang processes. If required for reasons of efficiency, $\mathrm{C}$ programs can be directly linked into the Erlang run-time system.

Since Erlang is implemented in $C$ it is essentially available on all systems that run C. Erlang is at present supported for the following operating systems: Solaris, Windows NT, VxWorks, and Linux.

Erlang allows the same rapid prototyping and interactive development as, for example, Lisp but extended into the world of concurrency and distribution. The error handling mechanisms and hot code loading allow the design of high availability, robust, non-stop systems.

\section{1982-86 TECHNOLOGY EVALUATIONS}

The first development step were experiments at CSLab (Computer Science Laboratory) at programming telephony using different programming languages and technologies based on a PABX (Private Branch Exchange) controlled by a VAX/UNIX system. The main conclusions were:

- Telecommunications systems are so large and heterogeneous that it seems likely that different programming techniques would be used for different parts of the systems.

- The shortest, clearest, and most beautiful programs (also those that were closest to a formal specification) were those written using functional or logic programming languages. 




Figure 2. The process of Applied Research

\section{1986-89 PROTOTYPING}

The next development step started with Prolog to which concurrency was added. Soon backtracking had to be dropped (a ring signal once sent out cannot be retracted) and the budding programming language changed to a functional style [2]. It was named Erlang after the Danish mathematician Agner Krarup Erlang, creator of the Erlang loss formula widely used for traffic calculations.

During 1988-89 CSLab collaborated with a prototyping team at EBC (Ericsson Business Communications AB). They worked on system architectures and used Erlang for building prototypes and patiently endured sometimes radical changes to the new language. The collaborative project was reported in December 1989 and showed a striking improvement in design efficiency over current practices.

\section{1990-94 PRODUCTIFICATION}

The Erlang implementation so far was an interpreter written in Prolog which was acceptable for a prototype, but not for a real product. The Erlang design team then focused on implementation issues and developed a virtual machine in $\mathrm{C}$ which turned out to be 70 times faster than the original interpreter. This proved that concurrent functional programming could be 
used for "soft real time" system products, i.e. response times measured in milliseconds. The compiler and other "tools" were written in Erlang itself.

Erlang was officially presented [1] at the ISS'90 (XIII International Switching Symposium) which took place in Stockholm in 1990. Erlang became recommended for prototyping purposes within Ericsson and was used to develop different demo systems, to control a photonic switch, to run cordless telephony etc.

In 1992 the decision was taken to develop Erlang into a product for use in production projects and a first project was started at EBC based on the above mentioned application prototype. The first production quality release of Erlang was delivered in October 1993.

In 1993 Erlang Systems $A B$ was created as a an Ericsson subsidiary to market Erlang commercially and to offer training and consulting on a professional basis. Erlang Systems rapidly developed documentation and course material of professional quality and presented the following initial course program:

- Basic Erlang, 4 days,

- Interoperability, 4 days,

- Tools and libraries, 4 days,

- Advanced Erlang, 5 days.

Erlang Systems made serious attempts at marketing Erlang with tools commercially which included lecture tours in Sweden and the US and presentations at tools fairs, however, with little success. One difficulty was the lack of good reference systems at Ericsson. In 1995 Erlang Systems was made into a department of Ericsson Infocom $A B$.

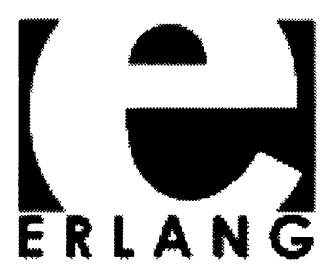

Figure 3. Erlang Systems logotype.

The first edition of the standard Erlang textbook Concurrent Programming in Erlang [3] was published in 1993. This was a period of intensive technical developments. An ASN.1 compiler was the first telecommunications oriented "tool" written in and for Erlang. Experiments with programming of distributed systems lead to the development of Distributed Erlang [17]. A translator [11] from SDL (Specification and 
Description Language) to Erlang was developed and also a distributed real time database [14] with transactions and query processing.

The first external delivery of Erlang was made already in 1989 (to Bellcore) and from then on Erlang has been delivered free-of-charge to universities for research, education, and prototyping. In 1995 this was made into a free distribution over the Internet.

Erlang dissemination pattern during this phase of development:

- Within Ericsson primarily for prototyping but for a few product projects.

- Outside Ericsson widely to academia but external marketing attempted. Experiences:

- Prototyping of very different applications assured the generality of Erlang.

- External (primarily academic) contacts created a necessary reference.

- Publishing a book lifted Erlang out of a narrow Ericsson context.

- A professional unit outside the research laboratory was necessary to handle education and consulting.

- Marketing a new programming language is very difficult.

\section{1995-97 PLATFORM}

In late 1995 Ericsson started a couple a of important application projects which required an appropriate programming technology. The situation was very urgent since a large "platform" project recently had been closed down. CSLab made a proposal based upon:

- Commercial processors,

- Commercial operating systems,

- Erlang,

- Productified development tools (debugger, interpreter, etc.),

- A base system called SASL (System Architecture Support Libraries) inspired from the application prototype systems,

- Productification of various software including the distributed database,

- Interworking with device processors (usually programmed in C),

- Interworking with other software (protocol stacks, routing software, etc. usually written in C).

CSLab was given the go ahead with a tight schedule to produce a prototype system in six months. The system was named OTP (Open Telecom Platform) [15].

At this point external marketing of Erlang for product development was stopped since all efforts were to be concentrated on the OTP project. However, the free distribution for research, education, and prototyping (primarily to universities) continued. 
A new unit was created for management, support, and further development of OTP. Technology transfer from CSLab to the OTP product unit was handled as follows:

- Already in the first prototype phase the product unit took over systems integration and release management.

- From the second development phase, the product unit took over project leadership and product management.

- Designers from the product unit joined the different design teams (for complier, SASL, etc.) and CSLab personnel were phased out over a longer period.

- CSLab and the OTP product unit are still co-located.

By the end of 1998 the OTP product unit numbered about 20 people. With successive releases new functionality has been added such as an implementation of CORBA (Common Object Request Broker Architecture).

In 1998 there were about 14 projects ongoing based on Erlang and OTP as well as many projects just using Erlang. At the CeBit international trade fair at Hannover in April 1998 there were no less than nine Erlang based system products on display in the Ericsson stand.



Figure 4. Number of Erlang related courses per year 1989-1999. There are about 12 pupils to each course. The first release of the Open Telecom Platform came in 1996. 
Perhaps the most significant application is Ericsson's ATM (Asynchronous Transfer Mode) switching system AXD 301 which is scalable from $10 \mathrm{Gbit} / \mathrm{s}$ to $160 \mathrm{Gbit} / \mathrm{s}$ [9]. The basic system in one rack handles $10 \mathrm{Gbit} / \mathrm{s}$ and contains two general-purpose control processors which handle network-signaling termination, call control, and operation \& maintenance (as well as smaller processors for device control).

During normal operation, one control processor handles calls while the other processor handles operation and maintenance. In addition, each processor acts as a standby for its counterpart. In the event that one of the processors should fail or be taken out of operation, the system automatically switches over to single-processor mode.

To date 250 AXD 301 systems have been delivered to 20 countries. The AXD 301 system is also an integral part of Ericsson's ENGINE concept which has been ordered by operators such as British Telecom and Telefónica.

In 1997 the ban on external marketing was lifted and Erlang Systems recruited new marketing staff. The marketing goals were set high and Erlang/OTP was to have 10,000 users and be used in product development in 5 companies other than Ericsson by the end of the year 2001 .

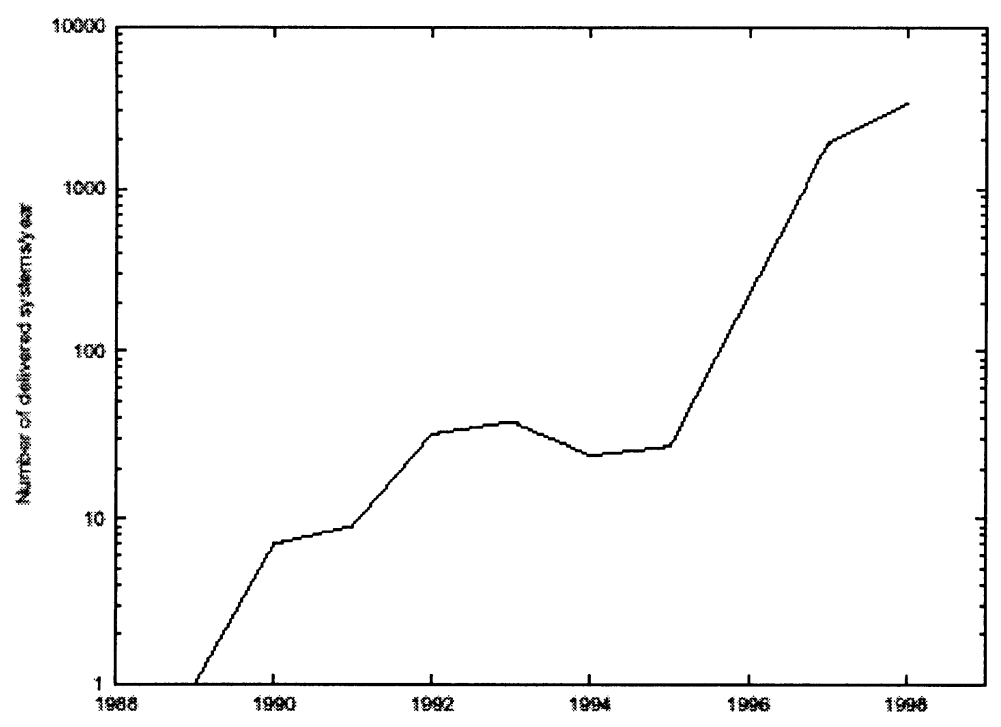

Figure 5. Erlang deliveries outside Ericsson per year prior to the open source. External marketing was stopped during 1994 and 1995. 
However, during 1998, most possible major partners, including SUN and MicroSoft, had declined the Erlang/OTP technology. Erlang Systems then concentrated on embedded systems in a partnership with Wind River Systems with an implementation of Erlang/OTP on the VxWorks operating system and on high availability telephony in a partnership with Natural Micro Systems who have a leadership in compact PCI technology.

These partnerships would not get all the way to the goal of 10,000 users in three years, instead the strategy changed towards the open source initiative (see below).

Erlang dissemination pattern during this phase of development:

- Within Ericsson used for strategic product development.

- Outside Ericsson passively to academia. External marketing stopped but later resumed.

Experiences:

- Erlang is an excellent base for the creation of a platform for building distributed high-availability applications.

- The existence of a library of useful system (platform) components makes Erlang immensly more useful.

- A product unit outside the research laboratory was necessary to handle product maintenance, further developments, error reporting, new releases etc.

- Marketing a programming language even with platform components is still very difficult.

\section{EXPERIENCES FROM ERLANG USAGE}

Experiences from the use of Erlang in many sometimes very large projects indicate clearly the two different traditions within software engineering. The most successful projects are run by enthusiastic teams working hands-on producing rapid results. The prime example is the AXD 301 project which developed a small executable system very early and then continued by building successive increments, carefully adding new functionality, and all the time monitoring system performance.

Less successful has been the top-down methodological waterfall approach where several teams (perhaps spread over several countries) specify and code the whole system and then send their parts for integration test. Then there is much poorer feed-back to the designers and the whole idea of interactive programming (one of the strong points of functional programming) is lost. 


\section{1998-2000 BACKLASH AND OPEN SOURCE}

In February 1998, ERA (Ericsson Radio $A B$ ), a large and important part of Ericsson, decided not to start any further application projects based on Erlang. The primary reason for this was a fear that a proprietary programming language might lead to a dead-end and also a general effort to reduce the number of development platforms.

During the Autumn of 1998 a discussion was raised about releasing Erlang as open source in order to facilitate its spread externally and hopefully attract even Ericsson competitors to use it. A small group visited Red Hat Inc., a company that distributes Linux, and in December open source Erlang was released, web site www. erlang. org.

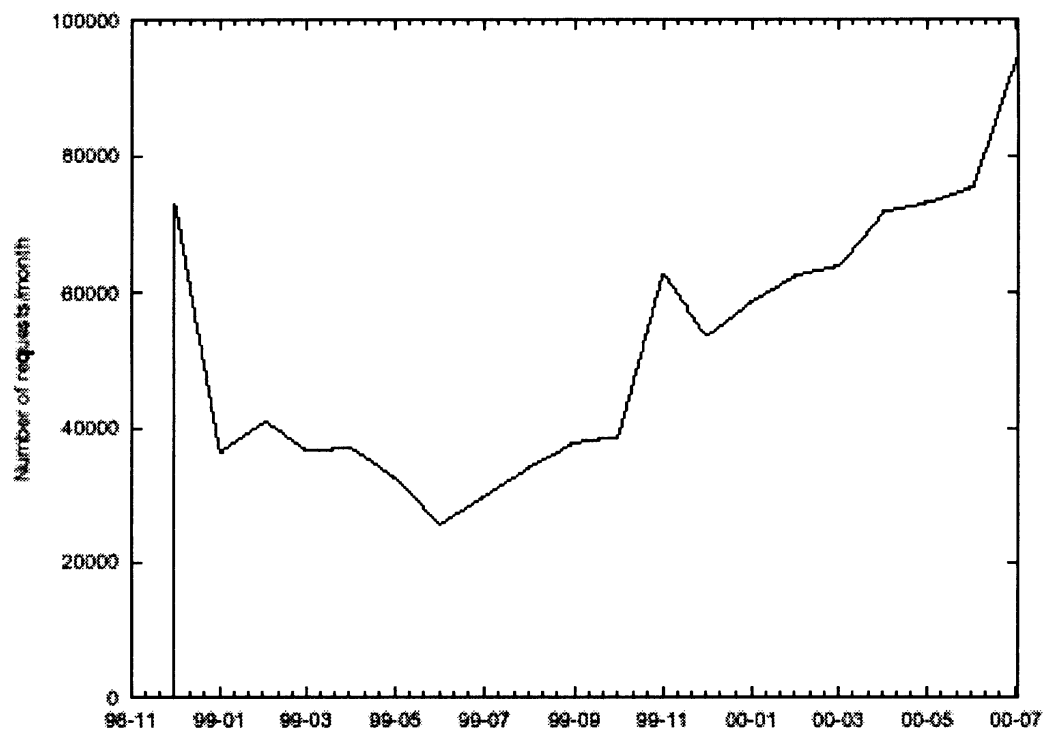

Figure 6. Number of requests per month to the open source Erlang web site. In addition there are four mirror sites in operation.

Whereas earlier marketing efforts had tried to make a business from marketing Erlang as a programming language with implementation, the focus now changed to spreading the language and to eradicating the "proprietary" image. Compared with earlier distributions of Erlang, the open source distribution is a considerably more mature product in that it contains the full OTP implementation (SASL, database, libraries, etc.) as well. 
During the first month there were 72,933 requests to the open source Erlang site. This dropped to about 40,000 requests for some months but has been climbing steadily since July 1999 . The increased activity is also noticed on the mailing lists.

Erlang Systems and the OTP product unit also operate a commercial (professional) web site www.erlang.se which gives information about current courses etc. Most external users use the open source but Erlang Systems also offers support contracts. Academic licenses are also available which make all teaching material available at no charge.

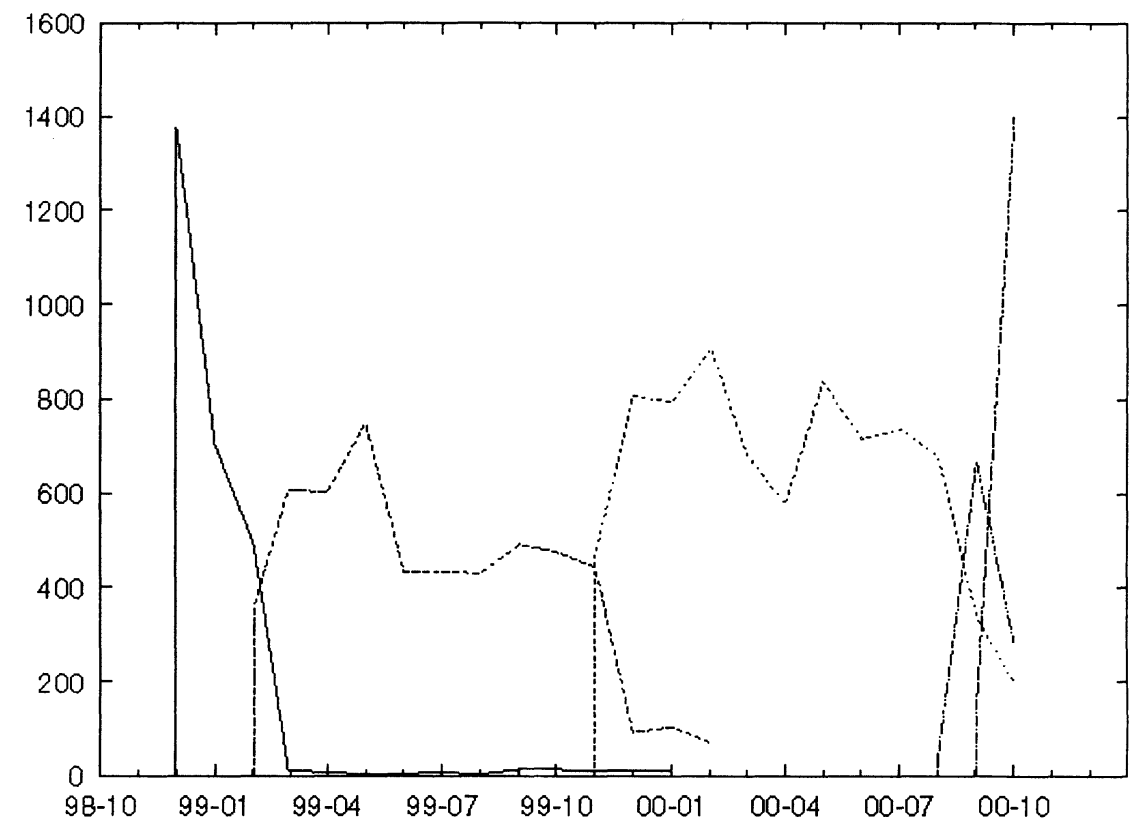

Figure 7. Downloads per month from the open source Erlang web site. $1^{\text {st }}$ release December 1998. $2^{\text {nd }}$ (debug) release February 1999. R6B release November 1999. R7A (beta) release August 2000. R7B release September 2000. There are about equal number of Windows and Unix downloads.

Early in 1999 most of the original Erlang developers (including Joe Armstrong, Robert Virding and Claes Wikström) left Ericsson to set up Bluetail, an external company based on venture capital. The business idea is to develop robust systems for ISPs (Internet Service Providers) using Erlang. Their first product was the Mail Robustifier followed by the Web Prioritizer. Bluetail has delivered systems to operators like TeleNordia and are 
marketing both in Europe and in the US. In the Spring of year 2000 Bluetail entered a partnership with Sendmail.

On August 28, 2000, Alteon WebSystems, a US company based in Silicon Valley, announced that they were in the process of acquiring Bluetail at a price of 152 million US\$. This followed on some collaboration between Alteon and Bluetail. At the same time Alteon was being acquired by Nortel.

When 100's of units (web switches etc.) from a major US manufacturer are sold based on Erlang, this might herald a new era in the history of Erlang.

Some external users are Sendmail, the British ISP One2one, and CellPoint which specializes on building position based systems for mobile telephony. An important Swedish user is Telia Promotor which has designed a call center based on Erlang which they are marketing all through Europe.

Erlang has triggered much further technical research. A type system [13] and a program verification system $[6,7]$ have been developed for advanced users and experiments with capabilities [8] have been carried out to handle imported software in a secure manner. Two alternative implementation projects, ETOS (Erlang TO Scheme) at l'Université de Montréal and HiPE (High Performance Erlang) [12] at Uppsala University, are also under way

Erlang has been much noted in the research world and in 1997 Joe Armstrong was invited speaker to the ACM SIGPLAN International Conference on Functional Programming which was held in Amsterdam. At the $12^{\text {th }}$ International Workshop on the Implementation of Functional Languages in Aachen, Germany, in 2000 there was a special session on Erlang.

Every year there is an International Erlang/OTP User Conference in Stockholm. The proceedings can be found in www. erlang. se/euc.

Erlang dissemination pattern during this phase of development:

- Within Ericsson no new large projects but growing developments of the existing projects.

- Outside Ericsson external marketing was replaced by an open source release which took off after about one year. Growing use of Erlang for product development.

Experiences:

- Reorganizations in a large company can change the situation radically.

- Erlang and OTP are highly relevant also for rapid development of highavalability Internet related applications.

- Open source is a very effective method for spreading a new software technology.

- The economical basis for Erlang/OTP still are the in-house Ericsson projects. 
- Some external users came as an effect of encountering Erlang at courses at the university.

\section{ON THE SPREAD OF FUNCTIONAL PROGRAMMING}

Philip Wadler presents the following list of possible reasons for the resistance to functional programming languages [16]:

- Compatibility,

- Libraries,

- Portability,

- Availability,

- Packagability,

- Tools,

- Training,

- Popularity.

Most of these are self-defeating, because of the lack of $X$, no X will be created. All points except the last one are of a technical nature and can easily be remedied. The key point is the last one which is a bit like a Catch 22 .

It might well be that it is difficult to introduce functional programming into an old and established company culture. This, on the other hand, leaves the field wide open for exploitation by new companies free from tradition.

\section{CONCLUSIONS}

For Erlang to be used inside Ericsson it needed to be used outside and for Erlang to spread outside Ericsson there had to be wide use of it inside. The only way to get around this was a steady spread of the language in both spheres. In fact, in the dynamic world of telecommunications, the history of Erlang has proceeded in a see-saw fashion with focus alternating between internal and external use.

The development and use of Erlang shows that for a new programming language to be reasonably successful there are, at least, the following prerequisites:

- There has to be a sizable and stable support organization.

- There has to be some niche that is sufficiently interesting and important for large sectors of industry. In Erlang's case high-availability, reliable, distributed systems and rapid design through high abstraction level and prototyping.

- The language must be reasonably simple to learn and to implement. 
Table 1. Erlang history summarized.

\begin{tabular}{|c|c|c|c|}
\hline & Internal Usage & External Usage & Comments \\
\hline $1984-6$ & - & - & Technology evaluations \\
\hline $1987-9$ & Use in prototypes & - & $\begin{array}{l}\text { Experimental } \\
\text { developments }\end{array}$ \\
\hline $1990-2$ & & Academic distribution & Presented at ISS'90 \\
\hline $1993-5$ & Limited use in products & External marketing & $\begin{array}{l}\text { Erlang Systems } \\
\text { established }\end{array}$ \\
\hline 1996 & $\begin{array}{c}\text { Use for strategic product } \\
\text { development }\end{array}$ & $\begin{array}{l}\text { External marketing } \\
\text { halted }\end{array}$ & $\begin{array}{l}\text { OTP development } \\
\text { OTP unit established }\end{array}$ \\
\hline 1997 & & $\begin{array}{c}\text { External marketing } \\
\text { resterted }\end{array}$ & $\begin{array}{c}\text { OTP development and } \\
\text { deployment }\end{array}$ \\
\hline 1998 & $\begin{array}{c}\text { Nine products displayed } \\
\text { at CeBit } \\
\text { Erlang stopped at ERA }\end{array}$ & Open source release & \\
\hline $\begin{array}{l}1999 \\
2000\end{array}$ & $\begin{array}{l}\text { AXD } 301 \text { and GPRS win } \\
\text { important orders }\end{array}$ & $\begin{array}{l}\text { Growing external use } \\
\text { Open source takes off }\end{array}$ & $\begin{array}{c}\text { Bluetail started } \\
\text { Alteon buys Bluetail }\end{array}$ \\
\hline
\end{tabular}

\section{COMMENTS ON TECHNOLOGY DIFFUSSION}

Four important observations from the Erlang developments:

- Erlang and functional programming in general both enable and require a new way of working with much more interactivity. The top-down waterfall methodologies were designed to handle conventional programming languages. Technology and methodology both have to be changed.

- Marketing a new programming language and a new way of working requires a huge effort and investment. Twice Erlang Systems has tried marketing Erlang with limited resources and with meager results. Sun has probably spent a fortune on Java but that has paid back in the form of increased demand for computer equipment. Ericsson is a telecommunications company and selling Erlang would not sell more switches.

- Open source combined with a good support organization has meant the real break-through. Many more programmers can try Erlang and companies know that support and education are available if needed.

- It is much more difficult to gain acceptance for a new programming language than perhaps 10 or 20 years ago. $\mathrm{C}++$ and Java are percieved as a standard. Perhaps it might have been easier if Erlang had been called "Concurrent Scheme" or "Concurrent Haskell". 


\section{REFERENCES}

[1] Joe Armstrong and Robert Virding. Erlang - An Experimental Telephony Programming Language. ISS'90 - XIII International Switching Symposium. Stockholm, May 27-June 1, 1990.

[2] Joe Armstrong, Robert Virding and Mike Williams. Use of Prolog for Developing a new Programming Language. The Practical Application of Prolog. London, April 1-3, 1992.

[3] Joe Armstrong, Robert Virding, Claes Wikström and Mike Williams. Concurrent Programming in Erlang. Prentice-Hall, 1996, ISBN 0-13-508301-X, 2nd edition.

[4] Joe Armstrong. The Development of Erlang. ACM SIGPLAN International Conference on Functional Programming. Invited paper. Amsterdam, June 9-13, 1997.

[5] Joe Armstrong. Erlang White Paper. Open source Erlang web site www.erlang.org. Stockholm, December, 1998.

[6] Thomas Arts, Mads Dam, Dilian Gurov, Lars-Åke Fredlund. System Description: Verification of Distributed Erlang Programs. Fifteenth International Conference on Automated Deduction. Lindau, July 5-10, 1998

[7] Thomas Arts and Mads Dam. Verifying a Distributed Database Lookup Manager written in Erlang. World Congress on Formal Methods. Toulouse, September, 1999

[8] Lawrie Brown and Dan Sahlin. Extending Erlang for Safe Mobile Code Execution. Second International Conference on Information and Communication Security. Sydney, Australia, November, 1999.

[9] Staffan Blau and Jan Rooth. AXD 301 - A new Generation ATM Switching System. Ericsson Review, no 1, 1998.

[10] Bjarne Däcker, Nabiel Elshiewy, Per Hedeland, Carl Wilhelm Welin and Mike Williams. Experiments with Programming Languages and Techniques for Telecommunications Applications. Software Engineering for Telecommunication Switching Systems. Eindhoven, April 14-18, 1986.

[11] Magnus Fröberg. Automatic Code Generation from SDL to a Declarative Programming Language. Sixth SDL Forum. Darmstadt, October 11-15, 1993.

[12] Erik Johansson, Mikael Pettersson and Konstantinos Sagonas. A High Performance Erlang System. Second International Conference on Principles and Practice of Declarative Programming. Montréal, September 20-22, 2000.

[13] Simon Marlow and Philip Wadler. A Practical Subtyping System For Erlang, International Conference on Functional Programming ICFP'97. Amsterdam, June 9-11, 1997.

[14] Håkan Mattsson, Hans Nilsson and Claes Wikström. Mnesia - A Distributed Robust DBMS for Telecommunications Applications. First International Workshop on Practical Aspects of Declarative Languages. San Antonio, Texas, January 18-19, 1999.

[15] Seved Torstendahl. Open Telecom Platform. Ericsson Review, no 1, 1997.

[16] Philip Wadler. Why No One Uses Functional Languages. SIGPLAN Notices - Functional Programming Column, August 1998, pp 23-27.

[17] Claes Wikström. Distributed Programming in Erlang. First International Symposium on Parallel Symbolic Computation. Linz, September 26-28, 1994. 